\title{
Mortality of low birthweight infants in England and Wales 1953 to 1979
}

\author{
PETER O D PHAROAH AND EVA D ALBERMAN \\ Department of Community Health, University of Liverpool, and London Hospital Medical College
}

SUMMARY National trends in the survival of low birthweight infants for the years 1953 to 1979 were examined. While stillbirth and day 1-28 mortality rates improved steadily throughout this period, day 0 mortality did not start to fall until the mid-1960s and then it improved in all birthweight groups. This suggests that special and intensive baby care units introduced progressively since about 1961 are exerting an appreciable effect on mortality. There is a serious lack of representative data on rates of handicap in the survivors.

One of the major concerns of health services today is the large increase in costs, particularly for services which depend on sophisticated technology for their development. The conflict between increasing costs and financial ceilings has made it imperative to examine the effectiveness of such services. Units for intensive or special care of infants are costly to equip and run, and such units are particularly good examples of areas where technical advances have played a prominent part in development. It is also appropriate that they have been to the fore in examining their own efficacy. Several reports have indicated that the units reduce mortality and morbidity ${ }^{1-3}$ but this view has been questioned, ${ }^{4}$ and in one, a review of cases from an intensive care unit, no appreciable reduction in mortality, or morbidity, was found for infants of very low birthweights (VLBW) $(\gtrless 1500 \mathrm{~g})$ over almost two decades. ${ }^{5} \mathrm{~A}$ serious drawback of these several reports is that they came from 'centres of excellence' with their inevitable bias. A more complete picture may be obtained by an examination of national trends in survival of low birthweight (LBW) infants-that is weighing $2500 \mathrm{~g}$ or less. This has already been reviewed up to $1972^{6}$ but now the most recently available data for England and Wales, updated to 1979 , are presented.

\section{Methods}

The birthweight of an infant is given on the birth notification, completed by the attendant at the birth, and returned to the area medical officer. Based on this, an annual return of LBW infants has been made to the Department of Health and Social Security on form LHS $27 / 1$ for livebirths since 1953, and for stillbirths since 1955 . Until 1962 the birthweight subdivisions were $<1500,1501-2000,2001-2250$, and $2251-2500 \mathrm{~g}$. Since 1963 the group $₹ 1500 \mathrm{~g}$ has been subdivided into $₹ 1000$ and $1001-1500 \mathrm{~g}$. These records also include, for each birthweight group, the number of infants who died within 24 hours-that is on day 0 - and the number who died during days 1-28 inclusive. From these data, the stillbirth, day 0, day 1-28, and neonatal mortality rates can be calculated for each group of LBW infants.

Data based on the civil registration of births and deaths, for stillbirths, day 0 , and day 1-28 deaths, of all birthweights are published by the Office of Population Censuses and Surveys. ${ }^{7}$ In order to find these mortality rates for infants of birthweights $>2500 \mathrm{~g}$ it is necessary to subtract the birth notifications from the total birth registration figures. There is a small discrepancy between the total notified and registered births and an inaccuracy is so introduced. However, it affects the mortality rates only of those infants of birthweights greater than $2500 \mathrm{~g}$.

It is necessary to use these dual sources of data because birthweight is not recorded at birth registration, and mortality of infants of birthweight $>2500 \mathrm{~g}$ is not notified. Attempts are currently being made to remedy this unsatisfactory state of affairs by transferring data on birthweight from the birth notification to the birth registration certificate. ${ }^{8}$

Among LBW infants there is a high mortality on day 0 . Because this can significantly affect the number of survivors, in the present analysis and contrary to usual practice, the day $1-28$ mortality is determined 
per 1000 survivors and not per 1000 live births. It is therefore not valid to add the day 0 (first day of life) and day 1-28 mortality rates to obtain the neonatal mortality rate, as different denominators are used in their calculation. To examine the trends a 2-year moving average has been calculated to reduce the fluctuation seen with an annual rate. A semilogarithmic scale is used so that the slope of the graph indicates the rate of improvement and allows a direct comparison of mortality between each birthweight group.

\section{Results}

The trend in the stillbirth rate for each birthweight group is shown in Fig. 1. In all groups there has been a steady improvement since data were first collected in 1955; for infants weighing over $2500 \mathrm{~g}$ the stillbirth rate has fallen by over two-thirds from $12 \cdot 3$ per 1000 total births in 1955-6 to 3.4 in 1977-8. The rate fell by $64,57,52$, and $33 \%$ respectively, in the birthweight groups 2251-2500, 2001-2250, 1501-2000, and $<1500 \mathrm{~g}$ between $1955-6$ and $1978-9$.

In contrast, the trend in day 0 mortality shows little improvement between 1953-4 and the early 1960s (Fig. 2). There was, indeed, a brief increase in day 0 mortality in the late 1950 s which was present in all birthweight groups (Table); it is particularly obvious for infants weighing 2001-2250 g (Fig. 2). This increase in mortality has been noted ${ }^{9}$ and was attributed to a change in policy regarding oxygen after evidence that oxygen could cause retrolental fibroplasia.
After about 1963-4, day 0 mortality began to improve for infants weighing over $1500 \mathrm{~g}$, while for the VLBW infants this improvement appeared to start about 3 to 4 years later. Since 1970, the downward trend in day 0 mortality in all birthweight groups has been sharper.

Day 1-28 mortality among those infants who survive day 0 is shown in Fig. 3. As with the stillbirth rate, there has been a steady improvement for all birthweight groups throughout the period for which data are available. Thus the improvement in day 0

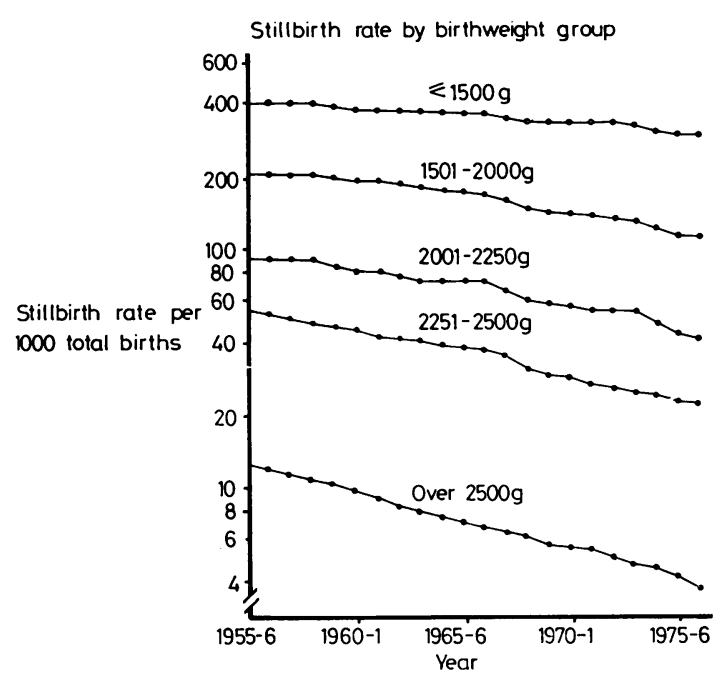

Fig. 1 Stillbirth rate according to birthweight group.

Table Two-year moving average birthweight specific mortality rates, England and Wales 1953-79

\begin{tabular}{|c|c|c|c|c|c|c|c|c|c|c|}
\hline Birthweight group (g) & $1953-4$ & $1956-7$ & $1959-60$ & $1962-3$ & $1965-6$ & $1968-9$ & $1971-2$ & $1974-5$ & $1977-8$ & $1978-9$ \\
\hline \multicolumn{11}{|c|}{ Stillbirth rate per 1000 total births } \\
\hline$₹ 1000\}$ & - & - & - & - & $401 \cdot 5$ & $379 \cdot 3$ & $397 \cdot 4$ & $362 \cdot 1$ & $344 \cdot 1$ & $321 \cdot 7$ \\
\hline $1001-1500$ & - & 一 & - & 一 & $360 \cdot 5$ & $331 \cdot 8$ & $311 \cdot 9$ & $285 \cdot 1$ & $262 \cdot 8$ & $242 \cdot 5$ \\
\hline$\gtrless 1500$ & - & $405 \cdot 1$ & $392 \cdot 1$ & $385 \cdot 1$ & $376 \cdot 4$ & $350 \cdot 1$ & $344 \cdot 1$ & $313 \cdot 6$ & $290 \cdot 9$ & $270 \cdot 0$ \\
\hline $1501-2000$ & - & $206 \cdot 9$ & $200 \cdot 0$ & $188 \cdot 0$ & $177 \cdot 1$ & $150 \cdot 6$ & $141 \cdot 7$ & $125 \cdot 2$ & $111 \cdot 4$ & $98 \cdot 8$ \\
\hline $2001-2250$ & - & $90 \cdot 4$ & $85 \cdot 3$ & $77 \cdot 4$ & $74 \cdot 6$ & $62 \cdot 9$ & $56 \cdot 3$ & $50 \cdot 2$ & $41 \cdot 7$ & 39.4 \\
\hline $2251-2500$ & 一 & $53 \cdot 5$ & $48 \cdot 7$ & $43 \cdot 2$ & $38 \cdot 7$ & $32 \cdot 3$ & $28 \cdot 1$ & $24 \cdot 0$ & $22 \cdot 2$ & $20 \cdot 0$ \\
\hline$>2500$ & 一 & $11 \cdot 9$ & $10 \cdot 3$ & $8 \cdot 4$ & $7 \cdot 2$ & $6 \cdot 3$ & $5 \cdot 5$ & $4 \cdot 7$ & $3 \cdot 4$ & 一 \\
\hline \multicolumn{11}{|c|}{ Day 0 mortality rate per 1000 livebirths } \\
\hline$<1000\}$ & - & - & - & - & $651 \cdot 0$ & $611 \cdot 2$ & $608 \cdot 8$ & $580 \cdot 9$ & $518 \cdot 1$ & $508 \cdot 1$ \\
\hline $1001-1500$ & - & - & - & - & $306 \cdot 7$ & 279.9 & $281 \cdot 9$ & $230 \cdot 8$ & $181 \cdot 8$ & $152 \cdot 7$ \\
\hline$<1500$ & $445 \cdot 2$ & $445 \cdot 0$ & $465 \cdot 2$ & $458 \cdot 9$ & $434 \cdot 8$ & $401 \cdot 6$ & $392 \cdot 1$ & $339 \cdot 7$ & $289 \cdot 7$ & $266 \cdot 4$ \\
\hline $1501-2000$ & 94.0 & $93 \cdot 3$ & $97 \cdot \overline{5}$ & $91 \cdot 0$ & $85 \cdot 4$ & $77 \cdot 3$ & $80 \cdot 1$ & $67 \cdot 1$ & $46 \cdot 4$ & $41 \cdot 4$ \\
\hline $2001-2250$ & $32 \cdot 8$ & $31 \cdot 6$ & $33 \cdot 7$ & $30 \cdot 2$ & $27 \cdot 7$ & $24 \cdot 6$ & $25 \cdot 8$ & $23 \cdot 0$ & $15 \cdot 2$ & $12 \cdot 5$ \\
\hline $2251-2500$ & $15 \cdot 3$ & $14 \cdot 8$ & $15 \cdot 6$ & $14 \cdot \overline{3}$ & $12 \cdot 2$ & $10 \cdot 3$ & $10 \cdot 8$ & $11 \cdot 6$ & $7 \cdot 1$ & $6 \cdot 2$ \\
\hline$>2500$ & $2 \cdot 0$ & $2 \cdot 0$ & $2 \cdot 0$ & $2 \cdot 1$ & 1.9 & $1 \cdot 8$ & $1 \cdot 7$ & $1 \cdot 2$ & 0.9 & - \\
\hline \multicolumn{11}{|c|}{ Days $1-28$ mortality rate per 1000 survivors of day 0} \\
\hline$₹ 1000\}$ & - & - & - & 一 & 569.8 & $539 \cdot 2$ & $478 \cdot 8$ & $442 \cdot 5$ & $495 \cdot 0$ & $511 \cdot 0$ \\
\hline $1001-1500$ & - & - & - & - & $249 \cdot 8$ & $234 \cdot 6$ & $214 \cdot 6$ & $200 \cdot 3$ & $161 \cdot 3$ & $155 \cdot 4$ \\
\hline$\gtrless 1500$ & $433 \cdot 7$ & $397 \cdot 7$ & $371 \cdot 6$ & $335 \cdot 6$ & $323 \cdot 3$ & $306 \cdot 5$ & $272 \cdot 4$ & $254 \cdot 2$ & $234 \cdot 3$ & $232 \cdot 1$ \\
\hline $1501-2000$ & $116 \cdot 8$ & $96 \cdot 3$ & $89 \cdot 5$ & 79.0 & $71 \cdot 7$ & $69 \cdot 7$ & $63 \cdot 9$ & 53.4 & 44.4 & $40 \cdot 2$ \\
\hline $2001-2250$ & $48 \cdot 8$ & $45 \cdot 5$ & 39.6 & $33 \cdot 1$ & $30 \cdot 1$ & $27 \cdot 1$ & $22 \cdot 6$ & 20.9 & 17.6 & $14 \cdot 2$ \\
\hline $2251-2500$ & $27 \cdot 3$ & $25 \cdot 6$ & $20 \cdot 1$ & $19 \cdot 4$ & $16 \cdot 5$ & $13 \cdot 4$ & $13 \cdot 4$ & $11 \cdot 8$ & $9 \cdot 2$ & $8 \cdot 4$ \\
\hline$>2500$ & $5 \cdot 9$ & $5 \cdot 2$ & $4 \cdot 8$ & 4.4 & $3 \cdot 7$ & $3 \cdot 4$ & $3 \cdot 4$ & $3 \cdot 7$ & $3 \cdot 0$ & 一 \\
\hline
\end{tabular}




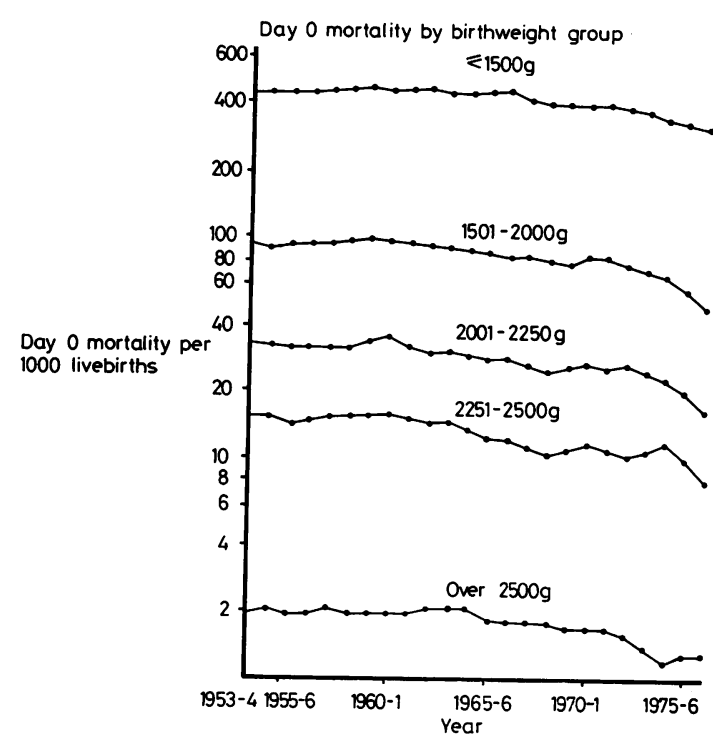

Fig. 2 Day 0 mortality according to birthweight group.

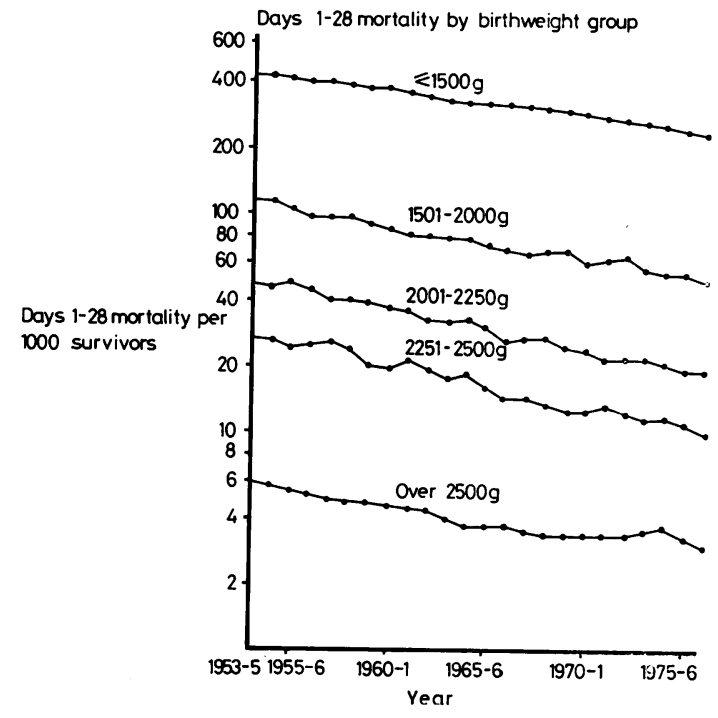

Fig. 3 Days 1-28 mortality according to birthweight group.

mortality has not been achieved by prolonging survival for a few extra hours or days, and it has taken place within the last 10 to 15 years. In terms of the number of lives saved, if the day 0 mortality rates of the 1950s and early 1960s had prevailed in 1979, there would have been an estimated 800 more deaths among the 4754 live infants weighing $1500 \mathrm{~g}$ or less, and, similarly, an estimated 340,170 , and 120 more deaths in the birthweight groups 1501-2000, 2001-2250, and 2251-2500 g respectively. Thus, as a result of the recent improvement in day 0 mortality it can be estimated that there were about 1400 fewer such deaths among infants weighing $2500 \mathrm{~g}$ or less in 1979.

Data available since 1963 show that the improvement in the mortality of the group $<1501 \mathrm{~g}$ is largely due to the decrease in the mortality of the group weighing between 1001 and $1500 \mathrm{~g}$. It is not due only to the reduction in the proportion of those under $1000 \mathrm{~g}$ which formed $37.7 \%$ of the $₹ 1500 \mathrm{~g}$ group in 1963 , and $35.5 \%$ in 1979 .

If it is assumed that $10-15 \%$ of infants of birthweights $₹ 1500 \mathrm{~g}$ who survive have major handicaps $^{2} 510$ the improved mortality in 1979 will mean 80-120 additional severely-handicapped children. There are fewer data on handicap rates among the heavier infants - that is $1501-2500 \mathrm{~g}$-but, assuming an $8 \%$ handicap rate, ${ }^{10}$ there will be about 50 more severely handicapped children in this group. As the numbers of minor and major handicaps are of the same order, ${ }^{25}$ it can be estimated that the 1400 extra lives saved of infants $₹ 2500 \mathrm{~g}$ in 1979 might include about 1100 intact normal survivors, and 150 survivors with minor and 150 with major handicaps.

Even if the true rate of handicap were considerably greater, these extra handicaps in survivors should be viewed in perspective. About $1 \%$ of all infants, including those of normal birthweights, have a major congenital handicap, so that in 1979 there would have been about 6400 such children born in England and Wales. We are unable to measure the benefits to those children who might have been handicapped after a stormy neonatal period some years ago but who now survive intact.

\section{Discussion}

Clinical management during the first minutes or hours of life of LBW infants may be crucial to survival. The increase in day 0 mortality rate associated with the change in the policy of oxygen administration in the late $1950 \mathrm{~s}^{9}$ underlies the sensitivity of this rate as a monitor of clinical management. The recent overall fall in day 0 mortality among these infants, especially in the very small, since mid-1960s must surely represent a real improvement in their care.

Although earlier reports had publicised the importance of special ? care for small babies, ${ }^{11-12}$ a national policy first emerged in 1961 with the Report on the prevention of prematurity and the care of premature infants ${ }^{13}$ which recommended the 
establishment of special care nurseries. Subsequent technical developments established the concept of intensive care with its reliance on highly specialised monitoring equipment, mechanical ventilation, and parenteral nutrition. Using routinely available data it is not possible to apportion improvement in mortality between special and intensive care but the outward dispersion of expertise and experience gained from intensive care is of wider import than may be immediately apparent.

While there has been a reduction in stillbirth and neonatal mortality among LBW as in normal weight infants, the crucial question that cannot be answered by any routine data in this country concerns the incidence of handicap in those who survive. Specific studies from individual hospitals provide conflicting answers; while some claim a reduction both in mortality and morbidity for the survivors, ${ }^{1-2}$ this is countered by the recent report which finds no significant change since $1961 .^{5}$ These reports however, are all hospital-based and, although a unit's self-audit is wholly praiseworthy, there is inevitable bias, and such reports do not substitute for a geographically-defined population study. The bias stems from the selection of infants admitted, and results can be further affected by changes in staffing both in numbers and in personalities.

The most common major handicap associated with LBW and one that can be attributed to less than optimal management in the perinatal period is cerebral palsy. A report from Sweden suggests that much of the overall decrease in the incidence of cerebral palsy in that country is accounted for by the decrease among LBW infants; ${ }^{14}$ unfortunately, such evidence is lacking in this country. The only national data are from the follow-up of the 1958 birth cohort ${ }^{15}$ which provides a baseline for the incidence of handicap. The 1970 cohort, ${ }^{16}$ when the follow-up is available, could be used for comparison. However, there has been a great improvement in mortality even since 1970, particularly in VLBW infants. Furthermore, each cohort is a one-week sample of births only and the number of LBW infants with handicap is small.

If measurement of the effectiveness of clinical management is to keep abreast of current trends it is imperative to obtain morbidity as well as mortality data that are population based. An ad hoc study of a single region would be a start and would also permit analysis of the costs and benefits of special and intensive care of infants.
We thank Professor J N Morris for advice on the preparation of this paper, and the DHSS for the latest data.

Full data for the Table is obtainable from Professor Alberman.

\section{References}

1 Fitzhardinge P M, Ramsay M. The improving outlook for the small prematurely born infant. Dev Med Child Neurol 1973 ; 15 : 447-59.

2 Stewart A, Turcan D, Rawlings G, Hart S, Gregory S. Outcome for infants at high risk of major handicap. In: Major mental handicap: methods and costs of prevention. Ciba Foundation Symposium 59 (new series). Amsterdam: Elsevier/North Holland, 1978: 151-71.

3 Prod'holm L S, Calame A, Steinhauer J. The outcome of low birthweight infants of less than $1500 \mathrm{~g}$. In: Bossart $\mathrm{H}$, Cruz J M, Huber A, Prod'holm L S, Sistek D, eds. Perinatal medicine. Vienna: Huber, 1972: 172-80.

4 Gordon R R. Neonatal and 'perinatal' mortality rates by birthweight. Br Med J 1977; ii: 1202-4.

5 Jones R A K, Cummins M, Davies P A. Infants of very low birthweight. A 15-year analysis. Lancet 1979; i: 1332-5.

6 Alberman E. Stillbirths and neonatal mortality in England and Wales by birthweight 1953-71. Health Trends 1974; 6: 14-7.

7 Office of Population Censuses and Surveys. Mortality statistics: childhood and maternity. Series DH3. London: HMSO, various years.

8 Office of Population Censuses and Surveys Monitor. Birthweight statistics. Reference DH3 80/1. London: HMSO, 1980.

9 Cross K. Cost of preventing retrolental fibroplasia? Lancet 1973; ii: 954-6.

10 Drillien C M. Aetiology and outcome in low birthweight infants. Dev Med Child Neurol 1972; 14: 563-74.

11 Crosse V M. The premature baby. London: Churchill, 1945.

12 Ministry of Health. Care of premature infants. Circular 20/44. London: Ministry of Health, 1944.

13 Central Health Services Council. Report of the subcommittee on the prevention of prematurity and the care of premature infants. London: HMSO, 1961.

14 Hagberg B, Hagberg G, Olow I. The changing panorama of cerebral palsy in Sweden 1954-1970. I. Analysis of the general changes. Acta Paediatr Scand 1975; 64: 187-92.

15 Davie R, Butler N, Goldstein H. From birth to seven. London: Longman, 1972.

16 Chamberlain R, Chamberlain G, Howlett B, Claireaux A. British births 1970. Vol. 1. London: Heinemann, 1975.

Correspondence to Professor E D Alberman, London Hospital Medical College, Turner Street, London E1 2AD.

Received 24 October 1979 